\title{
Plasma Debinding and Pre-Sintering of Injected Parts
}

\author{
Maria Antônia dos Santos, Matheus Piazzalunga Neivock, Ana Maria Maliska, \\ Aloísio Nelmo Klein, Joel Louis Rene Muzart* \\ Universidade Federal de Santa Catarina - Departamento de Engenharia Mecânica-LabMat \\ Campus Universitário, 88040-900 Florianópolis - SC, Brazil
}

Received: March 14, 2003; Revised: April 5, 2004

\begin{abstract}
Results of polypropylene removal in injected metallic parts by using plasma technology are presented. The samples were injected with $55.18 \%$ Vol. of unalloyed iron powder, $23.57 \%$ Vol. of paraffin and $21.25 \%$ Vol. of polypropylene. The paraffin was previously removed in hexane bath, followed by a treatment in abnormal glow discharge of argon and hydrogen for the removal of the polypropylene. The electric discharge was generated in two configurations: a confined anodecathode with the samples placed on the anode and a confined grid (anode)-cathode system with the sample placed on a holder at floating potential inside the grid. In the first geometry, electrons bombarded the sample surface, while in the second, they are collected by the grid. The samples were characterized by mass loss measurements and scanning electron microscopy. The results showed that the hydrogen discharge was more efficient for both configurations, which is attributed to the high reactivity of hydrogen atoms produced in the discharge. In addition, when plasma debinding was performed at $400{ }^{\circ} \mathrm{C}$ for $10 \mathrm{~min}$, by using the confined anode-cathode configuration, the polypropylene removal was total, while in the confined grid (anode)-cathode geometry the removal was approximately $32 \%$. The higher polypropylene removing observed in the anodecathode configuration is attributed to electron bombardment of the surface of the sample.
\end{abstract}

Keywords: powder injection moulding, plasma, debinding, sintering

\section{Introduction}

The production of parts by using the Powder Injection Moulding (PIM) technique constitutes an alternative process for the confection of parts of complex forms in great quantity ${ }^{1}$. In order to obtain a feedstock of suitable viscosity to perform the injection, thermoplastic materials are mixed with the metal powder ${ }^{2-4}$. The binders typically used are: paraffin, polypropylene, polystyrene, polyethylene and polyacetal. Before sintering, the organic binder must be removed without disrupting the particles, which is a delicate process $^{1}$. The techniques most commonly used are: chemical-thermal, supercritical, catalytic and in vacuum. The chemical-thermal technique, consists in immersion in vapor or liquid hexane at low temperature, typically $50{ }^{\circ} \mathrm{C}$, in order to dissolve at least one binder phase, producing an open porosity, followed by binder burnout. The mechanism of thermal degradation of the organic binder is based on the successive dissociation of the polymer, producing light molecules, which are evaporated out of the surface of the component. However, the thermal process is an inefficient dissociation mechanism resulting in a poor etching of the piece surface. Consequently, temperature may produce an excessive increase of vapor pressure in the core of the part, resulting in the occurrence of defects. In order to avoid the occurrence of defects as cracks or shape deformation, low heating rate $\left(<0.5^{\circ} \mathrm{C} / \mathrm{min}\right)$ are generally used, resulting in a long processing time, typically ranging from 10 to $50 \mathrm{~h}^{5,6}$. Supercritical debinding is not widely employed in commercial operation due to the high equipment cost and long processing times. In application of supercritical extraction, the operating pressures of solvents as carbon dioxide or propane are kept around $10 \mathrm{MPa}$ and temperatures are typically less than $100^{\circ} \mathrm{C}$. As a consequence of the low processing temperature, the diffusion of the binder until the surface of the component is slow, resulting in long processing times. Although, the catalytic debinding may be performed in short time, from four to eight hs depending on the thickness of the part, without occurrence of defect or distortion, undesirable pollutant reagents as nitric acid are used ${ }^{1}$. As

*e-mail: muzart@materiais.ufsc.br

Article presented at the XV CBECIMAT, Natal - RN, November/2002 
discussed by German and Bose ${ }^{1}$, in low-pressure system, a vacuum pump is used to continuously pull binder vapor away from the heated parts. At first, the heating rate is typically $0.5^{\circ} \mathrm{C} / \mathrm{min}$. or less until $100^{\circ} \mathrm{C}$, this temperature being maintained for times up to $4 \mathrm{~h}$. Subsequently, temperature is increased to $400{ }^{\circ} \mathrm{C}$ using a heating rate around $1{ }^{\circ} \mathrm{C} / \mathrm{min}$ and then maintaining it for another $2 \mathrm{~h}$. The pieces are constantly exposed to a gas flow, in order to remove the binder vapors, which are condensed and collected in a trap. Finally, when most of the binder is removed, the temperature may be progressively increased and sintering could be performed in a unique thermal cycle. This is the major advantage of the vacuum technique. However, considering that the binder degradation is performed by thermal mechanism, the process is relatively slow, lasting more than $10 \mathrm{~h}$. In addition, hydrocarbon molecules deposit on the support of the pieces and on the walls of the vacuum furnace requiring periodic cleaning of the equipment. The application of glow discharge on powder metallurgy processing is mainly used for cleaning $^{7}$, delubing ${ }^{8}$ and sintering ${ }^{9-15}$. Recently, a novel application to perform the debinding of components produced by injection molding was briefly published ${ }^{16,17}$, and is discussed in more details in this paper. The plasma technology applied to the extraction of binders is an alternative that consists in the use of high kinetic energy of the electrons to dissociate the hydrocarbon molecules, resulting in an activated debinding. The pieces are constantly exposed to a gas flow and light radicals or molecules produced by the dissociation of the binder are pumped out of the furnace. In addition, the reactive species generated in the glow discharge resulted in an efficient cleaning of the supports and walls of the plasma reactor. As in the vacuum technique, debinding and sintering could be performed in a unique thermal cycle, using the same equipment. As a consequence of the activated debinding cycle, the total processing time is significantly reduced.

\section{Experimental}

The plasma reactor was constituted of Pyrex cylindrical chamber closed in both ends by stainless steel lids. The system was pumped down by a two-stage mechanical pump until a residual pressure of less than $1.3 \mathrm{~Pa}(0.01$ Torr) was reached. For debinding step, hydrogen (99.998\% pure) or argon (99.999\% pure) was introduced in the vacuum chamber by using two Datametrics mass flow controllers. The pre-sintering gas mixture of argon/hydrogen was adjusted by using the two mass flow controllers. The pressure in the vacuum chamber was adjusted by manual valves and measured using an Edward capacitance manometer of $1330 \mathrm{~Pa}$ (10 Torr) full-scale. The electric discharge was generated by using a square waveform pulsed power source with the negative voltage output connected to the cathode and the positive was grounded. The power transferred to the plasma was adjusted by varying the time switched on $\left(\mathrm{t}_{\text {on }}\right)$ of the pulse, which could be varied from 10 to $180 \mu$ s and the total on/off time was $200 \mu \mathrm{s}$. The voltage was fixed in 610 and $480 \mathrm{~V}$ for hydrogen and argon respectively. The confined anode-cathode configurations are presented in Fig. 1. Both electrodes were manufactured of AISI 1020 steel and electrically insulated. The outer electrodes, of a rectangular form, $50 \mathrm{~mm}$ long, $40 \mathrm{~mm}$ in height and $30 \mathrm{~mm}$ in width were connected to the negative voltage and heated by ion bombardment. The inner electrode consisted of a plate $10 \mathrm{~mm}$ in width and a thickness of $2 \mathrm{~mm}$. The samples, placed on the inner electrode, were heated by radiation from the cathode and the temperature was measured using a ther-

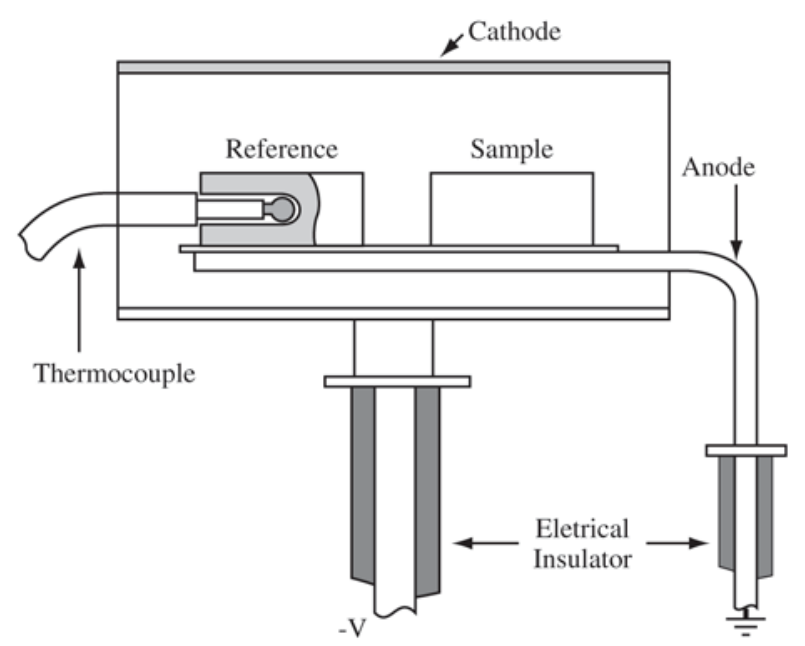

(a)

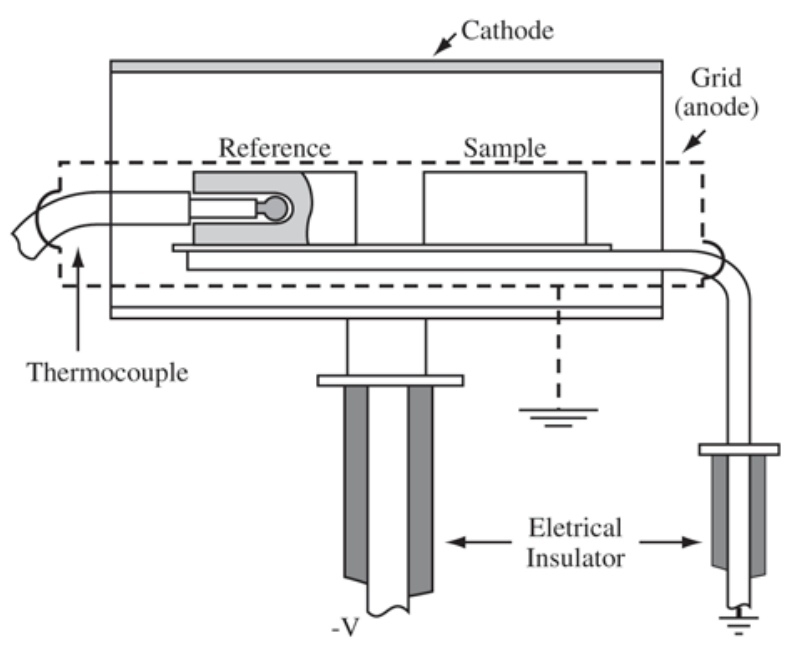

(b)

Figure 1. Electrode configuration: a) confined anode-cathode; b) confined grid (anode)-cathode. 
mocouple (Chromel Alumel type-K) inserted $5 \mathrm{~mm}$ into the reference sample.

Polypropylene extraction was performed in the two configurations presented in Fig. 1. By using the first geometry (Fig. 1a), the sample holder was grounded, working as the anode of the discharge and consequently was bombarded by low-energy ions and energetic electrons, as discussed by Chapman ${ }^{18}$. As a consequence of the confined geometry, the sample was also surrounded by reactive species generated in the plasma. The second geometry presented in Fig. 1b, consisted in a confined grid (anode)-cathode configuration, with the sample placed in a holder electrically insulated, i.e. at floating potential, and the grid was grounded. In this case, the grid was the anode and collected the low energy ions and the electrons. Therefore, by using such a configuration, the sample is only submitted to the reactive species produced in the plasma.

The samples were injected in the proportion of $55.18 \%$ Vol. of iron powder, $23.57 \%$ Vol. of paraffin and $21.25 \%$ Vol. of polypropylene. The paraffin was chemically removed using hexane as solvent heated at $50{ }^{\circ} \mathrm{C}$ for $6 \mathrm{~h}$, in order produce an open porosity. The plasma degradation of polypropylene was carried out in the confined anode-cathode and confined grid (anode)-cathode configurations with the sample placed on the anode or at floating potential respectively. The discharge was generated in argon or hydrogen gas, flowing at $3.3 .10^{-6} \mathrm{~m}^{3} \cdot \mathrm{s}^{-1}(200 \mathrm{sccm})$ maintaining the pressure at $400 \mathrm{~Pa}$ ( 3 Torr). The polypropylene removal was studied as a function of time and temperature. The heating rate was approximately of $20{ }^{\circ} \mathrm{C} / \mathrm{min}$. After the binder's removal, pre-sintering was performed at $860{ }^{\circ} \mathrm{C}$, in the electric discharge of a $20 \% \mathrm{H}_{2}+80 \%$ Ar gas mixture flowing at $3.3 .10^{-6} \mathrm{~m}^{3} \cdot \mathrm{s}^{-1}(200 \mathrm{sccm})$, at a pressure of $1200 \mathrm{~Pa}$ (9 Torr) during $30 \mathrm{~min}$. The heating and cooling rates were approximately $20{ }^{\circ} \mathrm{C} / \mathrm{min}$.

Polypropylene removal was quantified by mass loss measurements using a $5.10^{-5} \mathrm{~g}$ precision balance. As the total weight of the sample, around $2.583 \mathrm{~g}$, was constituted of $0.104 \mathrm{~g}$ of polypropylene and $2.479 \mathrm{~g}$ of iron, the mass loss measurements were obtained with very good accuracy. The mass loss percent was calculated considering only the mass of polypropylene. Microstructural characterization of the sample was performed by using a scanning electron microscope (Philips XL-30).

\section{Results and Discussion}

The results are presented in two parts: the study of polypropylene removal and the achievement of an optimized binder extraction cycle, followed by the pre-sintering step.

\subsection{Influence of temperature on the polypropylene removal}

Results of polypropylene extraction as function of temperature using the confined anode-cathode and grid (anode)- cathode configurations in glow discharge of hydrogen and argon are presented in Fig. $2 a$ and $2 b$ respectively. After reaching the fixed temperature, the debinding step lasted $60 \mathrm{~min}$.

In all experiments, for temperatures lower than $300^{\circ} \mathrm{C}$, a small fraction $(<20 \%)$ of polypropylene was removed, which is attributed to the low diffusion rate of the binder from the core to the surface. In hydrogen discharge, the polypropylene removal was total at $400{ }^{\circ} \mathrm{C}$ by using the anode-cathode configuration while in the grid configuration the extraction was around 69\% (Fig. 2a). Similar results were obtained in argon discharge (Fig. 2b), however of lower values, approximately 93 and 39\% respectively. As discussed previously, when the sample was placed onto the anode, the surface was submitted to electron impact. As

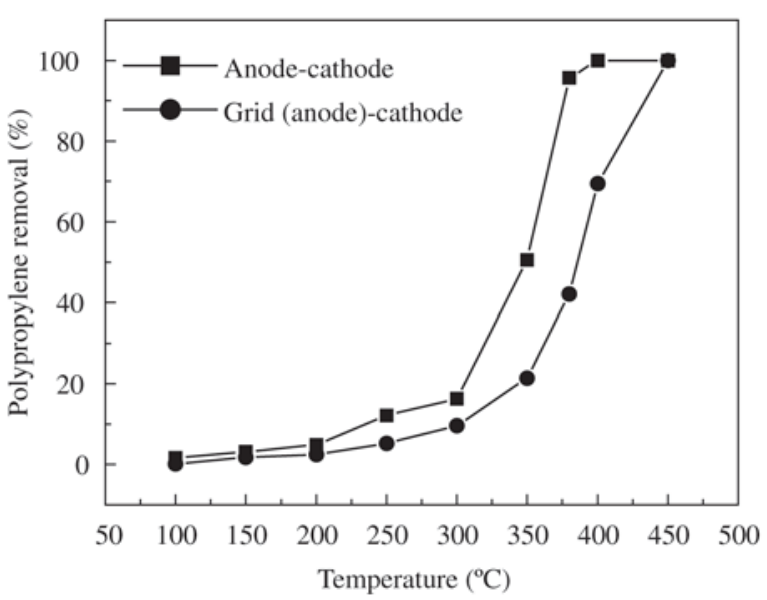

(a)

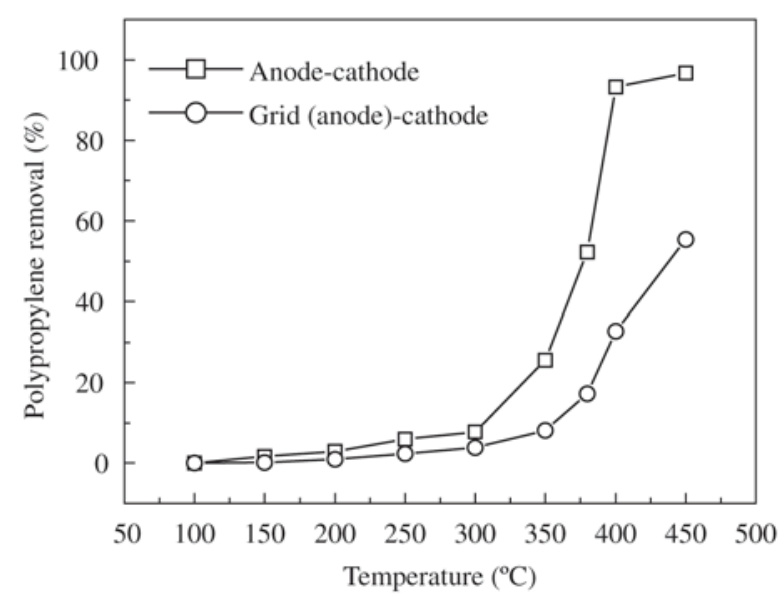

(b)

Figure 2. Variation of polypropylene removal as a function of temperature, performed in: a) hydrogen; b) argon discharge. The processing time was of $60 \mathrm{~min}$. 
a consequence, the energetic electrons, by inelastic collisions, resulted in the dissociation of polypropylene, producing light radicals or molecules as $\mathrm{CH}_{\times}(\times=1,2,3$ or 4$)$, which were pumped out of the vacuum chamber. By using the grounded grid configuration, the electrons are collected by the grid and the sample surface was not submitted to the electron bombardment. Therefore, it can be concluded that the electron impact on the surface of the sample resulted in an activated debinding. A comparative analysis of the polypropylene removal, performed in different gas discharge, showed that the hydrogen gas resulted in a higher binder removing, in both configurations. Such an effect is attributed to the production of hydrogen atoms, in the glow region, which, due to the confined configuration, efficiently reacted with the organic binder at the surface of the sample. In addition, the deposition of hydrocarbon observed on the supports of the parts and on the walls of conventional furnace during the debinding step does not occur by using the plasma process. So, periodic cleaning of the furnace is no longer more required due to the efficient etching produced by the reactive species generated in the glow discharge. To summarize, it is demonstrated that both, the effect of electron impact and the chemical reaction of hydrogen atoms, on the sample surface resulted in an activated binder removal.

\subsection{Polypropylene removal as a function of time in hydrogen discharge}

Figure 3 shows the variation of polypropylene extraction as a function of the processing time. The glow discharge was generated in hydrogen gas, at $400{ }^{\circ} \mathrm{C}$ and processing time ranged from 0 to $60 \mathrm{~min}$, in the confined anode-cathode and confined grid (anode)-cathode configurations. The

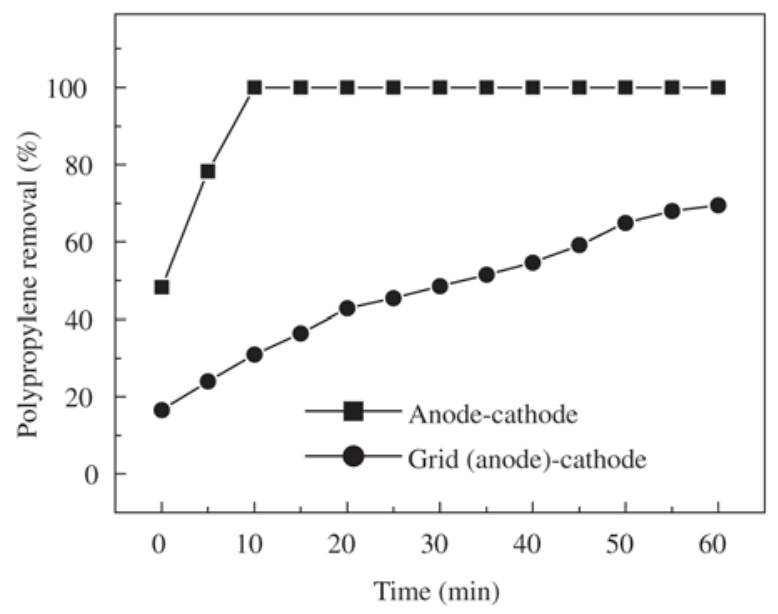

Figure 3. Variation of polypropylene removal as a function of time, in hydrogen glow discharge. heating rate was approximately of $20^{\circ} \mathrm{C} / \mathrm{min}$ until the temperature of $400{ }^{\circ} \mathrm{C}$ was reached and then was maintained constant as a function of time.

The polypropylene removal measured at time $t=0$ was of approximately $48 \%$ in the confined anode-cathode configuration and $16 \%$ by using the grid. This value corresponded to the time required to reach the temperature of $400{ }^{\circ} \mathrm{C}$, i.e., about $20 \mathrm{~min}$. In the confined anode-cathode configuration the polypropylene removal was total in a treatment time of $10 \mathrm{~min}$ at $400{ }^{\circ} \mathrm{C}$, while in the confined grid (anode)-cathode configuration the same value was not reached even for $60 \mathrm{~min}$. These results confirm what was observed in the study of polypropylene removal as a function of temperature, especially the importance of the impact of electrons on the sample surface resulting in the dissociation of the organic molecules of the binder. By using a hydrogen discharge, generated in the confined anode-cathode configuration with the sample placed on the anode, the polypropylene removal was achieved in a total processing time of $30 \mathrm{~min}$. The previously mentioned time of $30 \mathrm{~min}$ necessary to perform a complete debinding was obtained in a laboratory plasma reactor with only one sample. Certainly, in an industrial plasma reactor, the processing time for debinding step will be significantly higher. This is mainly due to the following factors: firstly, a suitable temperature homogeneity in the all the vacuum chamber had to be maintained in order to perform an uniform binder extraction in the all load; secondly, the degradation rate of polypropylen had to be sufficiently low, as to maintain a suitable purity of the gas discharge, in order to perform the debinding step without deposition of soot or hydrocarbon on the pieces, supports or walls of the reactor. However, the electron bombardment on the sample surface strongly increases the binder degradation, as previously discussed. Thus, it could be concluded from the present experimental results that industrial plasma reactor may have better performance than industrial vacuum or thermal furnace.

Micrographs of samples without binder, with polypropylene and after the plasma treatment at $400{ }^{\circ} \mathrm{C}$ in hydrogen discharge during $10 \mathrm{~min}$ are presented in Figs. 4a, $4 \mathrm{~b}$ and $4 \mathrm{c}$ respectively. It can be observed that the micrographs of Fig. $4 \mathrm{a}$ and $4 \mathrm{c}$ are similar, both different of the image presented in Fig. 4b, illustrating that the polypropylene was removed from the injected sample after plasma treatment.

\subsection{Variation of plasma parameter during the polypropylene removal}

Results of the variation of the macroscopic parameters (average voltage and current) of the electric discharge during the polypropylene removal are presented in Fig. 5. The measurements were performed in the confined anode-cathode configuration of hydrogen discharge, since the begin- 


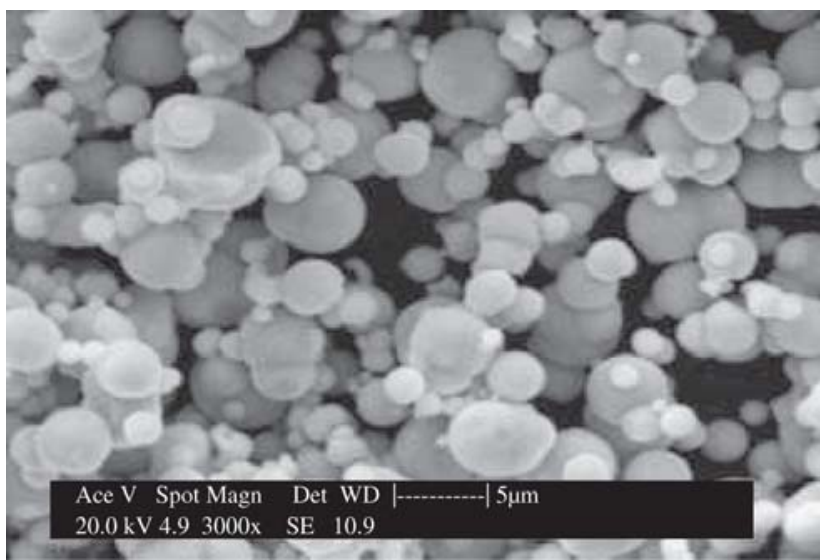

(a)

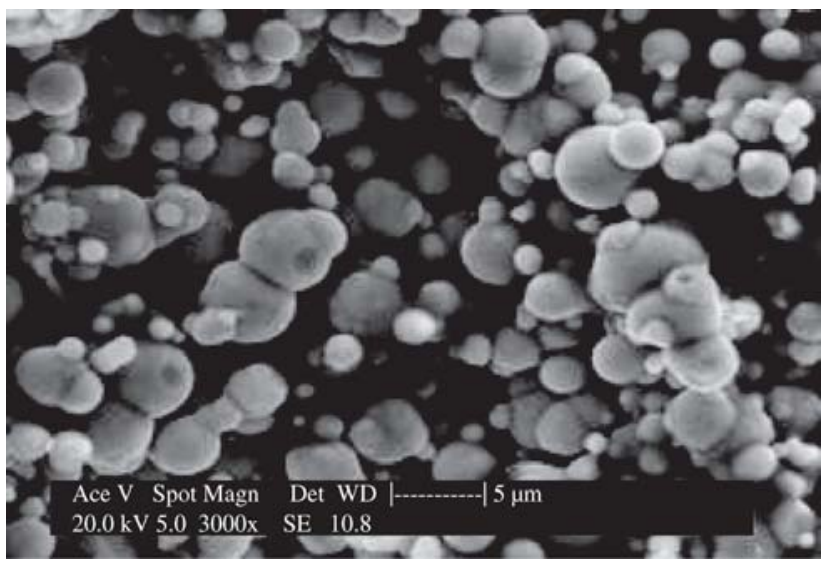

(b)

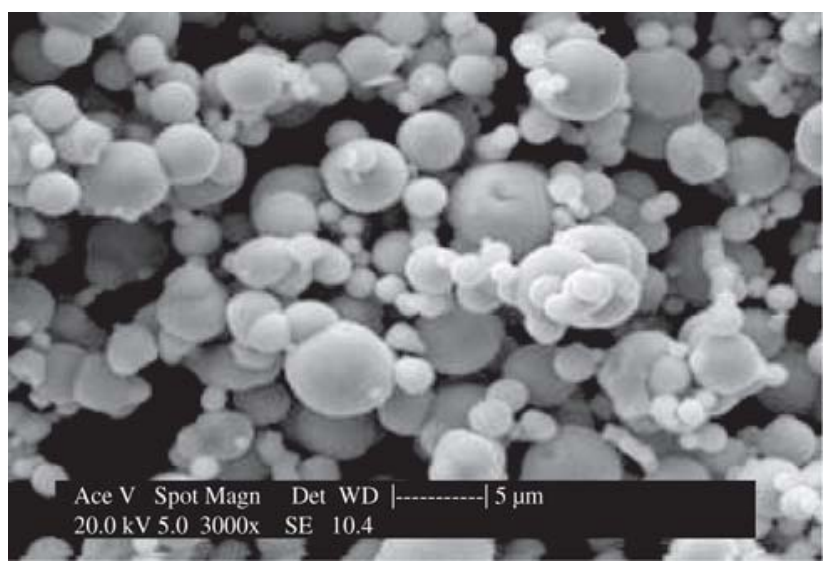

(c)

Figure 4. Scanning electron micrograph of: a) iron powder; b) injected sample; c) sample, plasma treated in hydrogen at $400{ }^{\circ} \mathrm{C}$ for $10 \mathrm{~min}$.

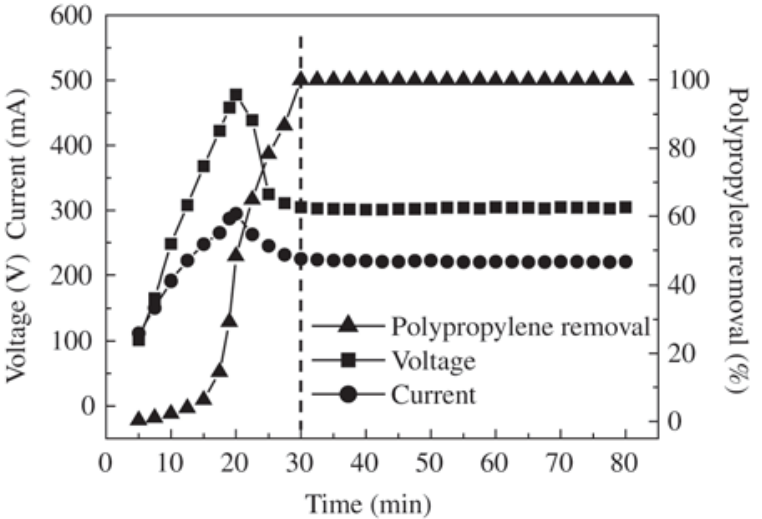

Figure 5. Variation of polypropylene removal and average voltage and current as a function of processing time in hydrogen discharge, in the confined anode-cathode configuration.

ning of the process at $20^{\circ} \mathrm{C}$ until the temperature of $400{ }^{\circ} \mathrm{C}$ was reached and kept for $60 \mathrm{~min}$. During the first $20 \mathrm{~min}$ the power transferred to the plasma was increased in order to reach the temperature of $400{ }^{\circ} \mathrm{C}$, with a corresponding increase of the average voltage and current. At that time, approximately $50 \%$ of polypropylene was removed. Following, in order to maintain the temperature at $400{ }^{\circ} \mathrm{C}$, the power transferred to the discharge had to be lowered and consequently the average voltage and current decreased. After thirty min, when the polypropylene removal was completed, a stabilization of the discharge parameters occurred. During the degradation of the binder, $\mathrm{CH}_{\times}$radicals were produced $^{19}$, modifying the discharge atmosphere and consequently the production of ionized species; thus, the power transferred to the discharge had to be adjusted to hold constant both the density and kinetic energy of ions which were responsible for sample heating. The stabilization of the discharge parameters are then related to the end point of debinding step, when the gas discharge returns to pure hydrogen, and at that time the temperature may be increased to process the pre-sintering in the same equipment.

\subsection{Debinding followed by pre-sintering step of the injected sample}

The application of polypropylene removal and presintering steps of injected samples in unique thermal cycle is presented. The cycle of debinding and pre-sintering is presented in Fig. 6. The polypropylene removal and the presintering were performed in an abnormal glow discharge, using the confined anode-cathode configuration with the sample placed on the anode. The debinding was performed in hydrogen gas at a pressure of $400 \mathrm{~Pa}$ (3 Torr) maintaining the temperature at $400{ }^{\circ} \mathrm{C}$ during $10 \mathrm{~min}$ and presintering was carried out at $860{ }^{\circ} \mathrm{C}$ for $30 \mathrm{~min}$ in a gas mixture of $20 \% \mathrm{H}_{2}+80 \% \mathrm{Ar}$ at the pressure of $1200 \mathrm{~Pa}$ (9 Torr). 
The heating and cooling rates were of approximately $20{ }^{\circ} \mathrm{C} / \mathrm{min}$. The pre-sintered sample presented a shiny appearance and no defect was visually observed. In Fig. 7, scanning electron micrograph of transversely cross-sectioned sample is presented. The microstructure of the sample showed the formation of necks, evidencing a suitable evolution of the plasma pre-sintering.

\section{Conclusions}

The results presented here demonstrated that the polypropylene removal from injected samples of unalloyed iron was efficiently performed by using plasma technology. When the samples were placed on the anode of a confined anode-cathode hydrogen glow discharge, maintaining the temperature at $400{ }^{\circ} \mathrm{C}$ during $10 \mathrm{~min}$, the polypropylene removal was total. It was shown that both the electron bombardment

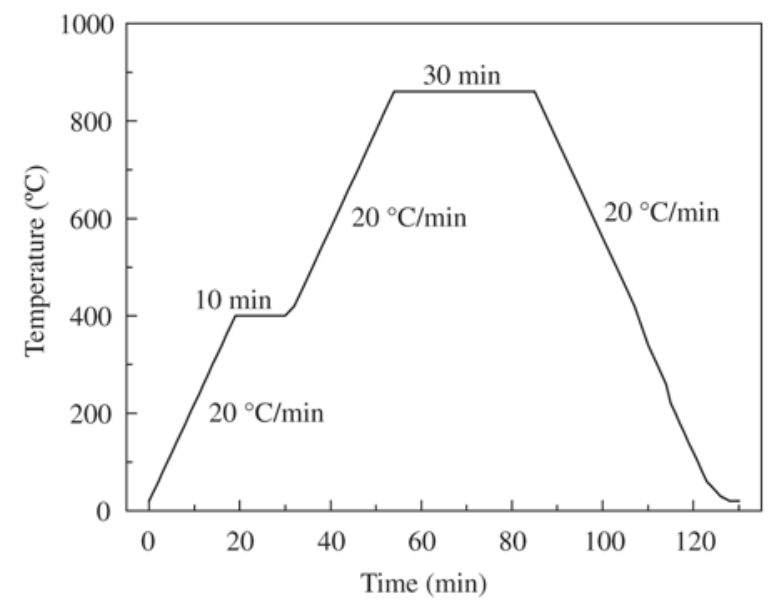

Figure 6. Thermal cycle of debinding and pre-sintering.

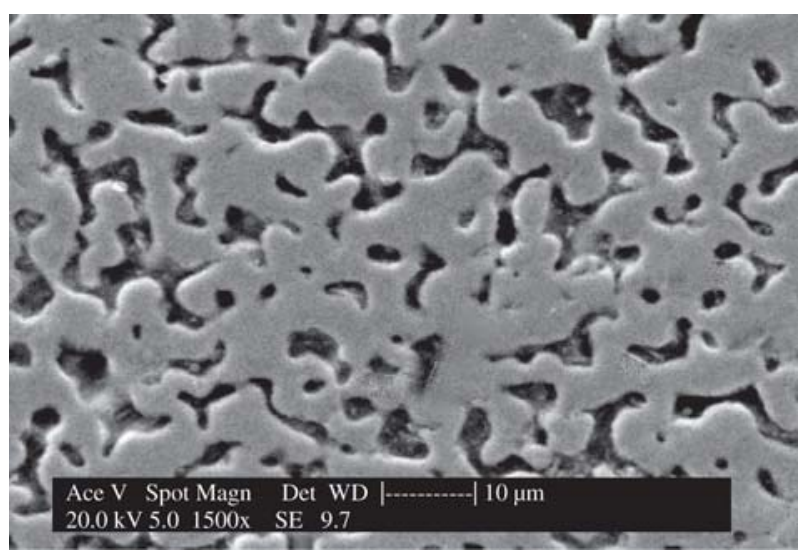

Figure 7. Scanning electron micrograph of transversely cross-sectioned sample, pre-sintered at $860{ }^{\circ} \mathrm{C}$ for $30 \mathrm{~min}$. of the surface of the sample and the high reactivity of hydrogen atoms produced in the glow discharge are responsible, for the efficient polypropylene removal. Finally, the debinding and pre-sintering steps could be successfully carried out in the same equipment and in a unique thermal cycle.

\section{Acknowledgments}

This work was performed with funds from Finep/MCT (PRONEX), CAPES and CNPq research grants.

\section{References}

1. German, R.M.; Bose, A.; Injection Molding of Metals and ceramics, Metal Powder Industries Federation, Princeton, NJ, 1997.

2. German, R.M.; Int. J. Powder Metall., v. 23, p. 237-245, 1997.

3. Ikegami, R.A.; Purqueiro, B.M.; Adv. Powder Technol., v. 189/191, p. 467-472, 2001.

4. Angermann, H.H.; Biest, O.V.; Reviews in Particulate Materials, v. 3, p. 35-70, 1995.

5. Milke, E.C.; Schaeffer, L.; Souza, J.P.; Adv. Powder Technol., v. 189-191, p. 636-642, 2001.

6. Finn, C.W.; Int. J. Powder Metall., v. 27, p. 127-132, 1991.

7. Santos, M.A.; Silva, H.R.T.; Muzart, J.L.R.; Maliska A.M; Mater. Sci. Forum, v. 416-418, p. 449-454, 2003.

8. Santos, M.A.; Maliska, A.M.; Muzart, J.L.R.; Mater. Sci. Forum, v. 416-418, p. 329-334, 2003.

9. Muzart, J.L.R.; Batista, V.J.; Franco, C.V.; Klein, A.N; Advances in Powder Metallurgy \& Particulate Material, v. 3, p. 77-84, 1997.

10. Batista, V.J.; Binder, R.; Klein, A.N.; Muzart, J.L.R.; Int. J. Powder Metall., v. 34, n. 8, p. 55-62, 1998.

11. Batista, V.J.; Mafra, M.; Muzart, J.L.R; Klein, A.N.; Back, N; Mater. Sci. Forum, v. 299, n. 3, p. 249-253, 1999.

12. Brunatto, S.F.; Kühn, I.; Muzart, J.L.R; Materials Research, v. 4, n. 4, p. 245-250, 2001.

13. Brunatto, S.F.; Kühn, I.; Klein, A.N.; Muzart, J.L.R; Mater. Sci. Eng. A, v. A343, p. 163-169, 2003.

14. Brunatto, S.F.; Kühn, I.; Klein, A.N.; Muzart, J.L.R; Mater. Sci. Forum, v. 416-418, p. 263-268, 2003.

15. Maliska, A.M.; Pavanati, H.C.; Klein, A.N.; Muzart, J.L.R.; Mater. Sci. Eng. A, v. 352, n. 1-2, p. 273-278, 2003.

16. Klein, A.N.; Muzart, J.L.R.; Souza, A.R.; Fredel, M.C.; Wendhausen, P.A.P.; Nascimento, R.M.; Process for removal of binders from parts produced by powder injection molding, US Patent, n. 6,579,493, June 17, 2003.

17. Klein, A.N.; Muzart, J.L.R.; Souza, A.R.; Fredel, M.C.; Wendhausen, P.A.P.; Nascimento, R.M.; Plasma proc- 
ess for removing a binder from parts obtained by powder injection molding, European patent Specification, n. EP 1230056 B1, 03/09/2003.

18. Chapman, B., Glow Discharge Processes, John Wiley
\& Sons, 1980.

19. Santos, M. A., Maliska, A.M., Souza, A.R., Ricard, A., Muzart, J.L.R., $15^{\text {th }}$ Inter. Symp. on Plasma Chemistry, Orléans, France, p. 2473-2477, july/2001. 